\title{
EXPERIENCES OF CHINESE YOUNG PEOPLE IN DEVISING THEIR SELF-DEVELOPMENT PLANS IN HONG KONG: A QUALITATIVE STUDY
}

\author{
Tabitha Ng \\ Department of Social Work, Hong Kong Shue Yan University, 10 Wai Tsui Crescent, \\ Braemar Hill, North Point, Hong Kong \\ E-mail: ylng@hksyu.edu
}

Publication date: 24 December 2019

To cite this article: Tabitha Ng. (2019). Experiences of Chinese young people in devising their self-development plans in Hong Kong: A qualitative study. Asia Pacific Journal of Educators and Education, 34, 167-185. https://doi.org/10.21315/apjee2019.34.9

To link to this article: https://doi.org/10.21315/apjee2019.34.9

\begin{abstract}
This study examines the lived experiences of young people in their transition to adulthood in Hong Kong. It focuses on their self-development plan, the possible constraints they may encounter in their life transition to adulthood, and suggestions for a better transition to young adulthood. A purposive sample of 10 young people was interviewed. Themes that emerged included lack of concrete self-development plans among young people, prevalence of collective 'self', influence of Chinese value of 'face' culture, dependent on families for extended periods, alternative career plan, time and poor academic background as constraints to pursuing self-development plans, high tuition fees and travelling expense affecting training opportunities, difficulties of pursuing one's own business due to domination of big enterprises, identity crisis in actualising self-development plans, importance of education as a form of self-development and need for training in interpersonal relationship and interviewing skills. This study has revealed insights on the self-development plans of young people affected by Chinese culture and values and the interplay of ecological systems in the Hong Kong context. The findings add to the understanding of the lived experience of young people in the transition to adulthood and can be used for mapping effective youth strategies and policies in Hong Kong.
\end{abstract}

Keywords: self-development plan, young people, Chinese cultural values, eco-systemic analysis 


\section{INTRODUCTION}

Youth is a period of searching identity where young people start to develop their sense of self through their social interaction with other relationships. Youth identities are exposed to various cultures under global and local influences (Jones, 2009). In late modern society, Giddens (1991) argues for a shift to self-development as reflexively organized and self-referential. In a post-modernist world, the self becomes a reflexive project (Henderson, Holland, McGrellis, Sharpe, \& Thomson, 2007; Thomson, Holland, McGrellis, Bell, Henderson, \& Sharpe, 2004) to be explored and constructed in response to social change.

The transition from school to work is a critical milestone in the life of young people and plays a crucial role in how their future careers develop. This transition is a complicated process which not only involves a change of identity from a learner to a worker, but also a transition from adolescence to adulthood where one's life planning is at stake. In life planning, young people are inevitably going through the process of searching for self-identity. It is often assumed that young people will choose some preferred pathway to achieve some status or position (Jones, 2009).

In Hong Kong, younger generation aged 15-29 accounted for $20.24 \%(N=$ $1,423,587$ ) of the entire Hong Kong population in 2009 (Census and Statistics Department, 2010). The sex ratio was quite equally distributed. The education attainment of this cohort was higher than older generations, however, their median income was lower. Statistics also showed that youth aged 15-19 are increasingly working in the fields of wholesale, retail, import/export trading, restaurants and hotels since 2001. Of this population, over $90 \%$ of the youth were living with parents (Yip, Wong, Law, \& Fu, 2011).

Just like the young people in the modern societies, the life experiences of the Hong Kong youngsters have changed quite significantly from earlier generations. These changes cover social relationships, education, labour market, lifestyles and the ability to become established as independent young adults (Resnick, 2005). While economic development is followed by increased global influence of values on today's young people, local traditions that define personhood and sociality such as Chinese cultural values e.g. strong ties with parents, filial piety, collectivism, high value placed on education and academic achievement, competitiveness and face culture, etc. are still relatively maintained in Hong Kong Chinese society (Bond, 1985; Inglehart \& Baker, 2000). Self-development or self-development plans of young people are seen as immersed in and defined by its social relationships (Hsu, 1985; Stockman, 2000). 
In the past decade or so in Hong Kong, there have been very few studies on life course development issues in a context of local value influence in late modernity. Hence, this study addresses some novel and challenging issues in the way today's Hong Kong young people experiences in their self-development plans. Based upon these conceptual insights, the study would draw upon Bronfenbrenner's eco-systemic theory (1993) to help explore Hong Kong young people's lived experience in their self-development plans in the local culture in late modernity. It is hoped therefore that the study may be of relevance to social work educators, service providers, policy makers and to interested parties more generally who together can jointly formulate appropriate youth policies and interventions to assist the transition from adolescence to young adulthood.

This study aimed to explore the lived experience of young people in their transition to adulthood in Hong Kong. It focuses on how self-development plan is understood and interpreted from the perspective of young people and the challenges they may encounter in the wider society when exposed to influences or constraints from various levels of the ecological systems in the wider society.

\section{METHODOLOGY}

This is a qualitative research with semi-structured individual interview design with a view to obtaining a deeper understanding of Hong Kong young adults' lived experience on their self-development plan and the possible constraints they may encounter in their life transition to adulthood. A semi-structured interview guide was developed with topics that sought to explore in more depth a number of key themes. These themes collected around the difficulties young people encountered in the transition to adulthood in late modernity in an eco-systemic framework analysis (Bronfenbrenner, 1993). In drawing on these sources, the respondents were, conceptually, positioned within what may be termed ecological systems theory (Segall, Dasen, Berry, \& Poortinga, 1999). This places the individual (with his/her personal qualities and abilities e.g. sex, age, health, character etc.) interacting actively with the environment, structured in terms of different levels of the microsystem, the mesosystem, exosystem, and macrosystem.

\section{DATA COLLECTION AND DATA ANALYSIS}

The individual interviews were conducted by the researcher from mid of 2011 to early 2012. The research plan was submitted by the researcher to Cardiff University's School of Social Sciences Research Ethics Committee for approval. 
As the research was conducted in Hong Kong, the study was also bound by the Code of Practice for Registered Social Workers which is monitored by the Hong Kong Social Workers Registration Board.

The researcher was responsible for the ten qualitative interviews. Semi-structured interviewing was the means of data collection and involved the implementation of a number of predetermined questions and special topics listed in an interview guide.

The questions were asked on topics as self-development plan and the ecological systems affecting their transition from a dependent teenager to a complete independent adult. Sample questions relevant to the present article include:

1. Self-development plan

a. Do you have any self-development plan? (e.g. self-exploration and self-understanding, develop one's interest and potential or have dreams and self-actualisation plan...)

b. Why do/don't you have a self-development plan?

c. What kind of positive experiences or difficulties might you encounter when you start your self-development plan?

d. What policies, measures or service provision can facilitate or help you develop your self-development plan(s)?

2. Various levels of ecological systems affecting transition from a dependent teenager to a complete independent adult

a. Microsystem (e.g. genetic makeup, gender, abilities and disabilities...)

b. Mesosystem (e.g. class of FOO, family functioning, parental roles, socialisation...)

c. Exosystem (e.g. neighbourhood, supportive network, religion, work, organisations...)

d. Macrosystem (e.g. sociocultural, political, economic systems and policies...)

Thematic analysis was adopted in this research because it was a commonly used method that identifies themes or patterns within data. It was used to seek qualitative insights in relation to the predetermined categories of discussion in a systematic and replicable manner. Overall, the thematic structure reflected the frequency of material that addressed the lived experience of the young people in designing their self-development plan in Hong Kong. In this instance, the method adopted was 
the six-stage model of Braun and Clarke (2006). In the first phase, the researcher became familiar with data by reading all of the transcripts and field notes which assisted in grasping broad patterns. The next stage involved initial coding and being reflexive about my own assumptions and views and to be open about these in the analytic process. In phase three, the codes were grouped by the researcher into potential themes and compared and connections traced. These clusters of initial themes and sub-themes were organised into an initial thematic map. Phase four entails reviewing, refining and reducing these themes. This process involved going back and forth between these different stages in a recursive process. Phase five entailed a fresh comparison both within and across themes in order to generate their shared and dissonant features and to establish links that helped grasp the systemic aspects of the perspectives of the respondents. In the final stage, the themes were defined in ways that capture the core of the theme and its relationship with the overall narrative on data and its analysis. The whole data analysis process was completed by the researcher.

\section{PARTICIPANTS}

Semi-structured qualitative interviewing was conducted with some ten individuals who were identified via theoretical sampling of a survey as being representative both of some particular thematic perspective and also some key characteristic of the youth profile as generated by the Hong Kong 2006 Population By-census Report (Census and Statistics Department, 2006). Ten interviewees were selected in terms of their socio-economic backgrounds such as gender, educational attainment, job status and working conditions, income, and immigration status. All interviewees were living with their parents. Nine of them were Hongkong people and one had studies overseas. Only one of them was new immigrant who was born in the Mainland China. The profiles of the interviewees were stated in Table 1. 
Table 1. Characteristics of participant

\begin{tabular}{|c|c|c|c|c|c|}
\hline Name & Age & Gender & Current status & Educational level & Remarks \\
\hline Lai & 23 & Male & $\begin{array}{l}\text { Drawing class } \\
\text { tutor }\end{array}$ & Secondary 5 & $\begin{array}{l}\text { Low monthly income } \\
\text { (around HK } \$ 3,000 \text { ) and } \\
\text { limited occupational } \\
\text { skills }\end{array}$ \\
\hline Ivy & 19 & Female & $\begin{array}{l}\text { Programme } \\
\text { assistant in a } \\
\text { welfare agency }\end{array}$ & Secondary 5 & $\begin{array}{l}\text { Low monthly income } \\
\text { (HK\$6,500) and limited } \\
\text { occupational skills }\end{array}$ \\
\hline Vilma & 24 & Male & $\begin{array}{l}\text { Management } \\
\text { trainee }\end{array}$ & $\begin{array}{l}\text { Bachelor } \\
\text { degree in public } \\
\text { administration }\end{array}$ & $\begin{array}{l}\text { High monthly } \\
\text { income (HK } \$ 24,000) \\
\text { with professional } \\
\text { qualification and } \\
\text { undertook overtime } \\
\text { work (around } 15 \\
\text { hours/week) and also } \\
\text { continuing education } \\
\text { (following a banking } \\
\text { course } 10 \text { hours/week) }\end{array}$ \\
\hline Alisan & 24 & Female & $\begin{array}{l}\text { Secondary school } \\
\text { teacher }\end{array}$ & $\begin{array}{l}\text { Bachelor degree } \\
\text { in education }\end{array}$ & $\begin{array}{l}\text { High monthly } \\
\text { income (HK } \$ 24,000) \\
\text { with professional } \\
\text { qualification and } \\
\text { worked overtime } \\
\text { (around } 15 \text { hours/week). }\end{array}$ \\
\hline Kevin & 19 & Male & Dog trainer & Secondary 4 & $\begin{array}{l}\text { Undertaking cross } \\
\text { border work (went to } \\
\text { the mainland China } \\
1-2 \text { times/week) and } \\
\text { overtime work (around } \\
10 \text { hours/week). }\end{array}$ \\
\hline Biola & 24 & Female & $\begin{array}{l}\text { Private housing } \\
\text { management } \\
\text { officer }\end{array}$ & $\begin{array}{l}\text { Post-secondary } \\
\text { education }\end{array}$ & $\begin{array}{l}\text { With continuing } \\
\text { education (taking } \\
\text { management course } \\
6 \text { hours/week) and } \\
\text { overtime work (around } \\
25 \text { hours/week) }\end{array}$ \\
\hline Tim & 21 & Male & $\begin{array}{l}\text { Not in education, } \\
\text { employment or } \\
\text { training }\end{array}$ & Secondary 5 & $\begin{array}{l}\text { Few tangible } \\
\text { connections with the } \\
\text { local community, had } \\
\text { no paid employment, } \\
\text { was not studying and } \\
\text { had no income }\end{array}$ \\
\hline
\end{tabular}


Table 1. (continued)

\begin{tabular}{llllll}
\hline Name & Age & Gender & Current status & Educational level & Remarks \\
\hline Cherry & 18 & Female & $\begin{array}{l}\text { Not in education, } \\
\text { employment or } \\
\text { training }\end{array}$ & Secondary 5 & $\begin{array}{l}\text { Few tangible } \\
\text { connections with the } \\
\text { local community, had } \\
\text { no paid employment, } \\
\text { was not studying and } \\
\text { had no income }\end{array}$ \\
Cheung & 23 & Male & $\begin{array}{l}\text { Printing machine } \\
\text { assembler }\end{array}$ & Secondary 5 & $\begin{array}{l}\text { He had migrated from } \\
\text { the mainland China in } \\
\text { the last three years }\end{array}$ \\
Paulina & 22 & Female & Student & $\begin{array}{l}\text { University Year 1 } \\
\text { student (major in } \\
\text { Geography) }\end{array}$ & $\begin{array}{l}\text { A single child, overseas } \\
\text { returnee from the US }\end{array}$ \\
& & & & &
\end{tabular}

\section{FINDINGS}

The interviews revealed that the respondents did not have concrete self-development plan. Two key themes with nine sub-themes were identified by thematic analysis of the transcribed interview scripts. The identified two key themes included: (A) Impacts of cultural values on devising young people's self-development plans; and (B) Constraints and opportunities for young people in transition to adulthood. Under these two main themes, there were 11 sub-themes as follows: (1) Lack of concrete self-development plan; (2) Prevalence of collective 'self'; (3) Influence of Chinese value of 'face' culture; (4) Dependent on families for extended periods; (5) Alternative career plan; (6) Time and poor academic background as constraints to pursuing self-development plans; (7) High tuition fees and travelling expense affecting training opportunities; (8) Difficulties of pursuing one's own business due to domination of big enterprises; (9) Identity crisis in actualising self-development plans - new immigrant status and single child problem; (10) Importance of education as a form of self-development; (11) Need for training in interpersonal relationship and interviewing skills. 


\section{THEMES}

\section{Impacts of Chinese Cultural Values on Devising Young People's Self- Development Plans}

\section{Lack of concrete self-development plan}

It was found that some interviewees in this study did not invoke any concrete selfdevelopment plan such as pursuing one's ideals or interests, life-goals or dreams, or seeking to understand one's weaknesses and strengths and thereby facilitate personal growth. There were some exceptions such as Lai (Case 1) and Alisan (Case 4). Lai wanted to pursue his dream of being an acclaimed designer. Though as a freelance designer, his income was low and with little employment stability. But that was his ambition and he did not want to do a job that he did not like.

I am thinking of learning guitar and art... so that I will not starve and could do the job that I like.

(Lai, male, low education level and income)

Alisan wished to be a writer but only pursued this as a private interest. She had a full-time teaching post. She was of the view that she must retain a full-time job to support herself before developing her interests as these could not realistically support her financially.

Hong Kong does not put emphasis on art development. As such, writing can only be an interest. You cannot dream of being a writer. You have to get a full-time job first.

(Alisan, female, high education, high income)

It is perhaps predictable that those youth with a job and with higher income and academic background will have more 'capital' to develop themselves whereas those with no income and no job have little or no resources to develop themselves.

\section{Prevalence of collective "self"}

In Hong Kong, the emphasis on filial piety and demands of obedience to parents and superiors continues to play an important role in the patterning of child and adolescent development. Under such local cultural influences, it was perhaps not surprising to find that interviewees did not seem to invoke some wholly separate 
sense of their own identities due to these social and cultural factors. Alisan (Case 4) challenged the view that Hong Kong youth only had a social identity in relation to academic achievement. Cheung (Case 9) explained frankly that he did not have any self-development plan of his own as he just followed the wishes of his parents.

The Hong Kong Government does not emphasise whole person development of an individual. The education system hinders the self-development of the youth as it does not encourage the development of a multiple intelligence of young people. The ultimate goal of students, their parents, teachers and even the whole education system seems to aim at entering university that at the end guarantee one can have a bright future and better quality of life.

(Alisan, female, high education and income)

When I start my kindergarten education, primary school and secondary school education, and up to now my first job in Hong Kong all are decided and chosen by my parents. Yet they have asked me about my preference, I really do not know what I want to be. Actually I do not have any goal, maybe due to my character. I do not take action to fulfil what I think. I just day by day follow the path prepared by my father to be a printing machine assembler.

(Cheung, male immigrant)

Cheung (Case 9) is a typical case that is shaped by Chinese values of family 'collectivism' which put emphasis upon family and state interests rather than individual interest (Sing, 1997). That is why in Cheung's mind there is only the concept of 'we', but not 'I' in his life choices (Triandis, 1987). According to late modernist thinking, we might conceive of Cheung as someone whose independence has been deferred and hence it is hard for him to grasp his life in a more individualistic and reflexive manner. It is likely that he will continue to experience a prescribed social background as ordered by parental and family influence. For Alisan (Case 4), her sense of self and high achievement while related positively to academic performance is nonetheless linked to the ways in which Chinese parents place much emphasis on education and diligence more generally (Sing, 1997). 


\section{Influence of Chinese value of 'face' culture}

Some young adults did not think it necessary to seek the assistance of the Government who in their view could not easily deliver change in their personal circumstances and hence they preferred to rely on themselves.

If you need someone to help, you will not make an effort to improve yourself.

(Kevin, male, a dog trainer undertaking cross-border work with overtime)

Kevin (Case 5)'s answer partly reflected his doubt about government capacity to offer help in matters of personal development but in doing so he also implicated the Chinese cultural value of 'face' culture whereby seeking help in these matters may be understood negatively (Stockman, 2000). One can lose face by appearing as less competent than one has claimed.

\section{Dependent on families for extended periods}

It is commonly found in many advanced societies that youth are often dependent on families for extended periods in which patterns of leaving the parental home have changed considerably (Beck, 2009). Similar constraints apply in Hong Kong (Hong Kong Federation of Youth Groups, 2001; 2007) and were prominent too in the interviews with respondents in this study. For example, in terms of selfdevelopment plan, some disadvantaged young adults simply did not consider such options because they or their families had no financial means by which to promote their ambitions. For instance, Tim (Case 7) liked cooking but he had no social or financial capital by which to achieve in this area of interest.

\section{Alternative career plan}

In the qualitative interviews, most of the interviewees had career plans except those with no job, no income and not involved in study. Their choice of career plans were based on different reasons such as their primary interest in the specific occupation, career prospects and job stability, and the income trajectory over time. It should be noted that some young adults were not satisfied with doing a job just for financial gain but were primarily attracted to the intrinsic rewards of a career that interested them. 
coz I love it (design). The second reason is that I do not want to do a job just for living, just for a good flat, just for fine clothes and it would be very boring, doing routines... you are just thinking of promotion... then when you were sixty, oh! You discovered that you have wasted your life. I want to do a job that I enjoy, ah... with a sense of achievement... and a sense of satisfaction...

(Lai, male with low income, low educational level and low skills)

Most of the male interviewees (Case 3, 5 and 9) accepted cross-border work for reasons such as overseas working experiences and career exposure that in turn increased their opportunities especially in the expanding labour markets of contemporary China. Vilma (Case 3 ) was an example. He was an ambitious young adult eager to enhance his career prospects.

I am very eager to have the opportunity to work across the border, or in USA or in ... because this would be a good opportunity for training and bringing benefits to my career ... I enjoyed overseas life and knowing people of different cultures.

(Vilma, male with high income, high educational level and high skills)

\section{Constraints and Opportunities for Young People in Transition to Adulthood}

\section{Time and poor academic background as constraints to pursuing self- development plans}

Young people's opportunities for self-development depend also on access to a range of external and personal resources such as social, cultural and economic capital which will affect their approaches to risk (Jones, 2009). Sennett (2004) argues that young people from privileged backgrounds have safety nets in the form of cultural capital which allow them to handle risk.

Interviewees cited difficulties such as time and poor academic background as constraints to pursuing any plans for self-development. Biola (Case 6) said that time was an important factor. She was fully occupied in her work and did not have the additional energy or time to pursue self-development opportunities. Kevin (Case 5) said that he had not achieved secondary education and could not meet 
the minimum English language requirement to go abroad to pursue his ambition of being a professional dog trainer.

\section{High tuition fees and traveling expense affecting training opportunities}

However, those with no job and no income said that they were hindered by the high tuition fees charged by self-development courses. The traveling expense was another consideration as they could not afford to go far beyond their local district to pursue training opportunities located some way off.

I think that the transport costs should be lower...

(Ivy, female with low income, low educational level and low skills)

Respondents proposed that the Government might consider cutting tuition fees of government subsidised programmes, offering more self-development programmes at school and with more promotion of self-development programmes for young people.

\section{Difficulties of pursuing their own business interests due to domination of big enterprises}

In Hong Kong, the key government policy that seeks to support vulnerable youth with schemes aiming at helping young people develop the occupational competencies needed for economic development. However, we should not ignore the socioeconomic problems of Hong Kong society such as inadequate job opportunities, expensive travelling costs, monopoly of the big enterprises, etc. that have long affected the life chances of young people (Sugarman, 1986) and upon which policy may have limited impact.

Ivy (Case 2) argued that the labour retail market was dominated largely by big conglomerates and that it was very difficult or impossible for young people to develop their entrepreneurial skills by setting up small businesses. Young adults with no financial support could not pursue their own business interests or develop related skills. 
... Dream? I once dreamt of starting a small business, but in Hong Kong it would be very difficult because the shopping malls are all controlled by big enterprises...

(Ivy, female with low income, low educational level and low skills)

\section{Identity crisis in actualising self-development plans - new immigrant status and single child problem}

Historically, many of the new arrivals from mainland China have lacked adequate education and skills and could only take up low-skilled jobs (Siu, 1999). A survey conducted by the Hong Kong Council of Social Service (2003) shows that Hong Kong people often consider new immigrants from China to be annoying, selfish and uncivilized in their attitudes and behaviour. As with the survey conducted by the Home Affairs Bureau (1997) that indicated about $74 \%$ of new arrivals having difficulties adapting to the way of life in Hong Kong, so a respondent who was a new immigrant in this study had problem in gaining work due to difficulties in speaking Cantonese, the dialect spoken in Hong Kong. Cheung (Case 9) claimed that this led to problems of discrimination against him as a new immigrant in the work setting.

When I came to Hong Kong, I cannot speak Cantonese... I face discrimination by others... Even the customers would avoid approaching me when they know that I speak Putonghua. They know I'm coming from China.

(Cheung, a new male immigrant)

Paulina (Case 10) is a typical case of being a single child who in future sees herself supporting her parents. She worries about how to cope with this responsibility when they retire and age.

I want to be a coach to teach young people the knowledge and skills in adventure-based programmes. But I think it is only a dream. I can't take it up as a future full-time job as the income is not stable. I'm the single child and when my father retires one day, my salary equates to their income. I can't be so selfish to pursue 
on my own interests. I need to consider my responsibility to care for them when they get older. I need to find a job with a stable and good salary.

(Paulina, a returnee from oversea study)

\section{Importance of education as a form of self-development}

Young people who invest in education look forward to the recognition that educational achievement can bring them, ultimately, to a career and financial security. Moreover, attending vocational or technical schools may be more effective in helping young people to find employment (Cooksey \& Rindfuss, 2001). Hence, education is important as a form of self-development and recognised as such by respondents such as Biola (Case 6).

School and parental attitude is very important to develop selfidentity of the youth so that they can have a whole person development and wellness training, not just focus on academic achievement.

(Biola, female undertaking overtime work and continuing education)

\section{Need for training in interpersonal relationship and interviewing skills}

As with research by the Hong Kong Federation of Youth Groups (2006), respondents expressed that they needed more career guidance services so as to find a job more easily. In the qualitative interviews, Tim (Case 7) indicated that he would welcome training in interpersonal relationships and interviewing skills. It is likely that some disadvantaged young adults will need basic training in developing social skills particularly in the way they relate to people when seeking a job.

\section{DISCUSSION}

The eco-systemic analysis on life course transition of young people showed the interplay of different systems on youth's self-development. At the microsystem and mesosystem level, personal qualities and family influence were important factors in affecting young people's transition from a dependent to a complete independent adult. It should be noted that some young people such as Tim (Case 7) and Cherry (Case 8) who were not independent and could not cope with problems while some 
like Alisan (Case 4) and Kevin (Case 5) were very independent and did not want to rely on others.

At the exosystem level, satisfaction level of the respondents to their selfdevelopment plans was related with work and social relationship. Those with temporary or contract-based jobs such as Ivy (Case 2) and Alisan (Case 4) were dissatisfied with living because of job insecurity. Those without a job and without income like Tim (Case 7) and Cherry (Case 8) indicated a low sense of life satisfaction. They chose to live in their own world with their computer and did not want to get in touch with others.

Some interviewees (Case 2, $6 \&$ 7) cited the influence of the macrosystem, e.g. socioeconomic problems of Hong Kong society such as inadequate job opportunities, expensive travelling costs, monopoly of the big enterprises, education system, employment-related policies as structural barriers to fulfill young people's self-development plans.

Regarding the local Chinese cultural values, filial piety of obedience to parents' advice and need to fulfill family responsibility to support aging parents also affect some interviewees such as Cheung (Case 9) and Paulina (Case 10)'s choices of fulfilling their own self-development plans. Collectivism is still strong in local Chinese families and among the younger generation (Triandis, 1987).

Extended family support or delay dependence on families by disadvantaged young adult children can be found in the study. For example, in terms of self-development plan, some disadvantaged young adults simply could not fulfil their plans because they or their families had no financial means by which to promote their ambitions. For instance, Tim (Case 7) liked cooking but he had no social or financial capital by which to achieve in this area of interest.

The fact that Kevin (Case 5) rejected to seek help from the Government as regards his self-development plan reflected the influence of Chinese value of 'face' culture and seeking help and support from others is a sign of incompetency of oneself.

Some respondents such as Biola (Case 6) also revealed the importance of parental attitude on their self-development plan, in particular the emphasis on education and academic achievement by Chinese parents.

Apart from the above-mentioned local Chinese cultural influences, some interviewees said that they would like to choose an individualised lifestyle which was from a global perspective different from their parents or older generation. 
They expressed a desire to have more variety in life and have exposure to global and different cultures and lifestyles e.g. go to different countries to work rather than staying in Hong Kong (Vilma, Case 3); find a satisfying job and not just earn a living (Lai, Case 1). It seems that global culture and values also penetrated into today's younger generation that shaped their views on self-development plans.

In sum, the individual interviews demonstrated that self-development plans of young people were affected by both local Chinese cultural values and the interplay of ecological systems in the Hong Kong context, and global and growing impact of individualised lifestyles and ideas of pluralism, liberalism within a wider economic context of a keen competitive culture of late modernity. All these influences bring risks, challenges, uncertainties and opportunities to young people's life transitions.

The eco-systemic approach provides a comprehensive framework to analyse the constraints and opportunities for young people in transition to adulthood in a local context. However, it tends to lack a global perspective that can capture the influence of wider effects such as the likely impact of global values, as in this enquiry into the lived experience of young adults about their self-development plans and life choices. Hence, the approach here has been to deploy a mix of concepts - the ecosystemic approach and the late modern notion of reflexive biographies (Henderson et al., 2007; Thomson et al., 2004), in order to capture something of the orientation of youth today.

\section{IMPLICATIONS OF THE STUDY}

Many young people have to find funds to pursue further study to enhance their employability. The Government should provide an education subsidy to help young people meet this financial burden (Yip et al., 2011).

Many young people see tertiary education as a basic requirement to get a job or career with prospects. However, places for tertiary education are limited and unable to meet demand. The Government should increase the number of places for tertiary qualifications. Compared with other Asian countries, Hong Kong still has a relatively small proportion of university graduates.

In this study, it was evident that some respondents had few if any financial resources to improve themselves and to secure a stable job. Some respondents also had no idea of what they should do or might want to do. Better career advice and services linked to schools such as Career Life Planning Programmes for secondary school students, would assist in the transition to higher education, work and career 
opportunities ( $\mathrm{Wu}, 2010)$. This would help young people to prepare for their self-development plans no matter whether they would pursue a full-time job or a number of part-time jobs ('slash').

The findings from this study added to the understanding of the lived experience of young people in the transition to adulthood in Hong Kong. Those who agreed to be interviewed hoped that this study would contribute to an increased understanding of their needs and enable the service providers to provide timely services to meet their needs. This qualitative study has given insights into the experience of young people in Hong Kong and these insights can be used for mapping effective youth strategies and policies.

\section{LIMITATIONS}

This study presents interesting data but it has its limitations. As it is a preliminary study on youth's lived experience in designing their self-development plan, individual interview approach with a small size and purposive sample has weak generalisations in qualitative analysis as data may be less representative. Nevertheless, the qualitative method allows in-depth study that gives rich and interesting narratives about the youth perceptions on their self-development plan in the condition of Chinese cultural influence and barriers and opportunities for their self-development. These views are a useful indication of the youth's perceptions in general. Despite its limitations, the study can provide a springboard for further research. The findings in this research can be interpreted as a first step or preliminary reference for the interested parties in mapping effective strategies and planning relevant social services and policies that meet the needs of today's young people. The influence of information and communication technology on the self-development plan of young people could be explored in future studies.

\section{REFERENCES}

Beck, U. (2009). Critical theory of world risk society: A cosmopolitan vision. Constellations, 16(1), 3-22. https://doi.org/10.1111/j.1467-8675.2009.00534.x

Bond, M. H. (Ed.). (1985). The psychology of the Chinese people. Hong Kong: Oxford University Press.

Braun, V., \& Clarke, V. (2006). Using thematic analysis in psychology. Qualitative Research in Psychology, 3(2), 77-101. https://doi.org/10.1191/1478088706qp063oa 
Bronfenbrenner, U. (1993). The ecology of cognitive development: Research models and fugitive findings. In R. Wozniak, \& K. W. Fischer (Eds.), Development in context (pp. 3-44). Hillsdale, NJ: Lawrence Erlbaum.

Census and Statistics Department. (2006). Population by-census 2006 - thematic report: Youths. Hong Kong: C\&SD Publication.

Census and Statistics Department. (2010). Table 002: Population by age group and sex. Retrieved 2 October 2011, from http://www.censtatd.gov.hk/hong_kong_ statistics/statistical tables/index.jsp?charsetID $=1 \&$ tableID $=002$

Cooksey, E. C., \& Rindfuss, R. R. (2001, December). Patterns of work and schooling in young adulthood. Sociological Forum, 16(4), 731-755. https://doi.org/10.1111/ j.1573-7861.2009.01133.x

Giddens A. (1991). Modernity and self-identity: Self and society in the late modern age. Cambridge: Polity Press.

Henderson, S., Holland, J., McGrellis, S., Sharpe, S., \& Thomson, R. (2007). Inventing adulthoods: A biographical approach to youth transitions. London: Sage.

Home Affairs Bureau. (1997). Equal opportunities: A study of discrimination on the ground of race. Hong Kong: Government Secretariat.

Hong Kong Council of Social Service (HKCSS). (2003). The cross-cultural perception and acceptance between local residents and new arrivals (in Chinese). Hong Kong: HKCSS Publication.

Hong Kong Federation of Youth Groups. (2001). Does knowledge have a price? Youth Poll Series, 94, September 2001. Hong Kong: Hong Kong Federation of Youth Groups.

Hong Kong Federation of Youth Groups. (2006). The transition from school to work. Youth Study Series, 35, April 2006. Hong Kong: The Hong Kong Federation of Youth Groups.

Hong Kong Federation of Youth Groups. (2007). The challenges and difficulties faced by young people in Hong Kong with low educational attainments, low levels of skill and low incomes. Youth Study Series, 37, June 2007. Hong Kong: Hong Kong Federation of Youth Groups.

Hsu, F. L. K. (1985). The self in cross-cultural perspective. In A. J. Marsella, G. DeVos, \& F. L. K. Hsu. (Eds.), Culture and self: Asian and Western perspectives (pp. 24-55). New York and London: Tavistock.

Inglehart, R., \& Baker, W. E. (2000). Modernization, cultural change, and the persistence of traditional values. American Sociological Review, 65, 19-51. https://doi. org/10.2307/2657288

Jones, G. (2009). Youth. Cambridge: Polity Press.

Resnick, M. D. (2005). Healthy youth development: Getting our priorities right. Medical Journal of Australia, 183(8), 398-400. https://doi.org/10.5694/j.1326-5377.2005. tb07101.x

Segall, M. H., Dasen, P. R., Berry, P. R., \& Poortinga, Y. H. (1999). Human behavior in global perspective: An introduction to cross-cultural psychology. US: Allyn \& Bacon.

Sennett, R. (2004). Respect: The formation of character in an age of inequality. Harmondsworth: Penguin. 
Sing, L. (1997). Self-concept development: Is there a concept of self in Chinese culture? In L. Sing (Ed.), Growing up the Chinese way: Chinese child and adolescent development (pp. 357-374). Hong Kong: The Chinese University Press.

Siu, Y. M. (1999). New arrivals: A new problem and an old problem. In L. Chow, \& Y. K. Fan (Eds.), The other Hong Kong report 1998 (pp. 201-228). Hong Kong: The Chinese University Press.

Stockman, N. (2000). Understanding Chinese society. UK: Polity Press.

Sugarman, L. (1986). Life-span development: Concepts, theories and interventions. London: Methuen.

Thomson, R., Holland, J., McGrellis, S., Bell, R., Henderson, S., \& Sharpe, S. (2004). Inventing adulthoods: A biographical approach to understanding youth citizenship. Sociological Review, 52(2), 218-239. https://doi.org/10.1111/j.1467954X.2004.00466.x

Triandis, H. C. (1987). Collectivism vs individualism: A reconceptualization of a basic concept in cross-cultural psychology. In C. Bagley, \& G. K. Verma (Eds.), Personality, cognition, and values: Cross-cultural perspectives on childhood and adolescence (pp. 2-42). London: Macmillan.

Wu, X. (2010). Hong Kong's post-80s generation: Profiles and predicaments. Hong Kong: Central Policy Unit Publication.

Yip, S. F., Wong, W. C., Law, Y. W., \& Fu, K. W. (2011). A study on understanding our younger generation. Hong Kong: Central Policy Unit Publication. 